\title{
Envelhecimento e rede de apoio social em território rural do Pantanal matogrossense
}

\author{
I 1 Marta Gislene Pignatti, ${ }^{2}$ Reni Aparecida Barsaglini, \\ ${ }^{3}$ Giselle Dantas Senna I
}

Resumo: No processo de envelhecimento populacional, em território rural, as redes de apoio social são fundamentais para a reprodução do grupo que, por força da tradição destaca-se a família como unidade essencial de cooperação econômica e principal fonte de apoio social. As transformações no território afetam, reciprocamente, as possibilidades desse apoio. No contexto desse artigo, foram enfocados aspectos do apoio social entre famílias de campesinos idosos tendo como referência a noção de rede social em território rural e como universo empírico duas comunidades rurais (São Pedro e Retiro São Bento), no distrito de Joselândia, município de Barão de Melgaço/ MT. Trata-se de estudo orientado pela perspectiva socioantropológica, que permitiu apreender os pontos de vista dos sujeitos, valendo-se da abordagem qualitativa. Foram entrevistados 18 idosos, pertencentes a 11 famílias, sendo 8 delas de São Pedro e 3 de São Bento. De modo geral, os moradores idosos entrevistados não desvinculam a dimensão física da terra, da sua simbologia - que é todo o sentido de sua existência. O parentesco, a amizade e a identidade interligam as pessoas em relações de reciprocidade, por diversos motivos, em situaçôes cotidianas, chamando a atenção para o papel dos vínculos para a manutenção da saúde. As redes de apoio se ampliam, no caso do cuidado com as doenças, e outras são estabelecidas para o acesso aos serviços de saúde. Essa elasticidade/plasticidade da rede para o apoio coaduna-se à noção de territorialidade pela sua conotação material e simbólica.

\footnotetext{
> Palavras-chave: envelhecimento, território rural, apoio social, redes
}

\footnotetext{
1 Doutora em Saúde Coletiva. Departamento de Saúde Coletiva (UFMT) - área de Saúde Coletiva; ênfase em saúde, ambiente e sociedade. Endereço eletrônico: martagp@terra.com.br

2 Professora do Departamento de Saúde Coletiva (UFMT); área: Saúde Coletiva - ciências sociais em Saúde. Endereço eletrônico: renib@terra.com.br

${ }^{3}$ Mestre em Saúde Coletiva (UFMT). Endereço eletrônico: gisele_sena@yahoo.com.br
} 
Este trabalho analisa a relação do envelhecimento com as redes de apoio social, cotejadas pela discussão de território, procurando evidenciar tal relação em comunidades rurais do Pantanal mato-grossense. Esta área de pesquisa está inserida no Programa Ecológico de Longa Duração - PELD Pantanal, no subprojeto "Vigilância e promoção da saúde em população do entorno da Reserva Particular de Patrimônio Natural do Serviço Social do Comércio - RPPN/SESC Pantanal” (PIGNATTI, 2011), localizando-se no entorno de área de preservação ambiental, cuja população tem seu modo de vida imbricado com o ritmo das águas. Tal fato lhe confere uma situação diferenciada, pelas restrições impostas ao uso do território, particularizando-a tanto nas relações econômicas e culturais como na forma de desenvolvimento da agricultura familiar (PIGNATTI; CASTRO, 2010).

A diferenciação histórica do espaço tem início a partir da sua delimitação, isto é, a partir de sua apropriação como território, em parte determinada pela necessidade de domínio e posse de recursos naturais - para a conquista das condiçōes de sobrevivência - e, por outra parte, por sua ocupação física como habitat dando origem, posteriormente, à defesa territorial, que é exercida diretamente pelos membros da coletividade (SANTOS, 2006; HEIDRICH, 1998).

A noção de território é uma representação coletiva, uma ordenação primeira do espaço, pela qual os grupos humanos constroem sua relação com a materialidade, num ponto em que a natureza e a cultura se fundem (MALDI, 1997).Dessa forma, a materialidade é apenas um componente do território, já que todas as suas demais representações são abstratas.

Assim, mesmo quando parte das características de apropriação, domínio, identidade, pertencimento, demarcação, separação estiver presente, Heidrich (2004) considera a ocorrência do princípio da territorialidade. Acrescenta-se que ela, além de incorporar uma dimensão política, diz respeito também às relações econômicas e culturais, pois está "intimamente ligada ao modo como as pessoas utilizam a terra, como se organizam no espaço e como atribuem significado ao lugar" (HAESBAERT, 2005, p. 9).

Pelos seus aspectos material, simbólico e relacional (dos vínculos sociais interpessoais e institucionais), o conceito de território vai ao encontro da noção 
de redes sociais entendidas como "teias de relações e trocas de obrigações postas pela organização social e pela cultura, e não somente como elos entre indivíduos favorecidos pelos vínculos e ligaçôes afetivas entre eles" (CANESQUI; BARSAGLINI, 2010). Nesse sentido, o território é suporte de redes (SANTOS, 2006), e estas podem se configurar como recursos de apoio social - material, cognitivo, afetivo e emocional (ADAM; HERZLICH, 2001) - disponíveis ou mobilizados pelas pessoas em situações cotidianas.

$\mathrm{Na}$ região em questão, para a manutenção da agricultura familiar, os grupos de produtores frequentemente usam as redes de relações sociais, que combinam atitudes de confiança com condutas de reciprocidade e cooperação (MAUSS, 2003), para resolver ou amenizar situações críticas relativas às necessidades básicas na área da alimentação, saúde, educação, infraestrutura de suporte à pequena produção, e de acesso aos serviços.

Assim, supõe-se que o envelhecer e "ser velho" assume peculiaridades em território rural. O envelhecimento pode ser considerado um fato universal e natural - pelo ciclo biológico do ser humano e de boa parte das espécies naturais (envolvendo nascimento, crescimento e morte) - e também um fato social e histórico - pela variabilidade das formas de vivê-lo e concebê-lo (DEBERT, 2006). Um processo que gera problemas comuns, mas que podem ser vividos e resolvidos diferentemente pelas culturas (MEYERHOFF; SIMIC apud UCHOA, 2003).

As formas de periodizar a vida, e a definição das práticas relacionadas a cada período, apresentam também variações segundo os grupos sociais de uma mesma sociedade (DEBERT, 2006), o que permite afirmar que as várias etapas da vida são social e culturalmente construídas. De fato, as diversas sociedades constroem diferentes práticas e representações sobre a velhice, a posição social dos velhos na comunidade e nas famílias e o tratamento que lhes deve ser dispensado pelos mais jovens (MINAYO; COIMBRA JR, 2002), denotando a imprecisão do conceito de velhice cujos limites flutuam em termos de complexidade fisiológica, psicológica e social (VERAS, 2007).No entanto, Debert nos afirma que

o curso da vida como construção social e cultural não pode ser entendido como algo que os seres humanos podem fazer e refazer, um processo que não impõe limite à criatividade e ao qual qualquer sentido pode ser atribuído. É preciso olhar, com mais atenção, para os limites que a sociedade coloca à nossa capacidade de inscrever a cultura na natureza (DEBERT, 1996). 
Tendo como contexto de pesquisa um território rural em suas dimensões material e simbólica da territorialidade, o envelhecimento e as redes de apoio social em saúde revestem-se de importância para o aprofundamento das particularidades da realidade social vivenciada pelo grupo e famílias de idosos. Diante disso, neste artigo, foram enfocados aspectos do apoio social entre famílias de campesinos idosos, parte do estudo desenvolvido por SENA (2009) em dissertação de mestrado.

O grupo de idosos residia no denominado Distrito de Joselândia, município de Barão de Melgaço/MT e possuía uma população de 2.483 habitantes em 2000 (IBGE, 2000), distribuídas em sete comunidades: São Pedro (sede do Distrito), Mocambo, Pimenteira, Retiro São Bento, Colônia Santa Isabel, Capoeirinha e Lagoa do Algodão; interligadas por uma rede de parentesco (consanguinidade, afinidade e compadrio) que, por autodefinição, se identificam por "povo de Joselândia" (BRASIL, 2007).

\section{Metodologia, procedimentos e técnicas da pesquisa}

Trata-se de estudo orientado pela perspectiva socioantropológica. $\mathrm{Na}$ área da pesquisa, foram desenvolvidos estudos tendo como perspectiva a vigilância e a promoção da saúde da população do entorno de área de proteção ambiental, que, devido à sua característica de reserva, impôs significativas restrições ao uso do território, afetando, consequentemente, o modo de vida dos seus moradores (PIGNATTI e CASTRO, 2010). As referidas pesquisas enfocaram como temáticas a contaminação ambiental e a diarreia; as práticas de cura dos benzedores; o apoio social em saúde e o envelhecimento; as representações sociais de saúde e de ambiente; e a sexualidade entre adolescentes; compondo um conjunto de dissertações de mestrado (seis) desenvolvidas junto ao programa de pós-graduação em Saúde Coletiva do Instituto de Saúde Coletiva da Universidade Federal de Mato Grosso (PIGNATTI, 2011).

Para o recorte do estudo sobre o apoio social em saúde e envelhecimento, partiu-se de uma perspectiva socioantropológica, a qual permite apreender os pontos de vista dos sujeitos, tomando como referência o grupo social ao qual pertencem, suas experiências e o contexto sociocultural no qual se inserem. 
Para a escolha dos sujeitos, foram consultados dados de um questionário sobre perfil socioeconômico e morbidade referida, aplicado em estudo anterior, aos moradores de 85 residências das sete comunidades que compóem o Distrito de Joselândia (PIGNATTI e CASTRO, 2010). O critério de inclusão foi idade igual ou superior a 60 anos e, como critério de exclusão, a incapacidade de comunicação oral ou apresentar complicações crônicas de enfermidades que comprometessem totalmente a sua autonomia.

A partir dessa consulta, optou-se por trabalhar com idosos de duas comunidades pantaneiras (São Pedro e Retiro São Bento), selecionadas em função de possuírem maior número de sujeitos que atendiam aos critérios de inclusão, bem como pela facilidade de acesso físico à localidade. Assim, obteve-se a identificação dos idosos e a localização das respectivas moradias nas duas localidades eleitas, perfazendo um total de trinta e quatro (34) potenciais participantes, considerado suficiente ao tipo de estudo.

Deste total, na primeira visita exploratória ao campo (15 a 17/07/2008) foi possível localizar 18 idosos pertencentes a 11 famílias. As entrevistas foram pré-agendadas na visita exploratória e realizadas em segunda visita ao campo (agosto de 2008) levando-se em conta a unidade familiar, sendo as informações fornecidas pelo casal ou por um dos idosos, no caso de viuvez ou separação.

Nota-se que os filhos/filhas solteiros residem com os pais (a maioria do sexo masculino). A partir do casamento, a família do filho constrói outra casa próxima à primeira residência para abrigar o novo casal ou parentes. Caso tenha mais posses, esta é construída em outro sitio e o casal fica responsável pela lida da terra no local.

A família foi escolhida como foco do estudo por tratar-se de comunidade rural, cuja produção, segundo Woortman (2004), é tipicamente familiar, e não apenas no sentido do uso da força de trabalho conjunta, mas também porque o sítio produz conforme as necessidades dos variados membros da família: crianças, mulheres (gestantes ou de "resguardo"), doentes e idosos; implicando em variadas alocações de partes da terra disponível. Ou seja, o tipo e os itens de cultivo são eleitos de acordo com as necessidades e o perfil dos membros da família. As características das famílias de idosos entrevistados são apresentadas no Quadro 1. 

de São Pedro e Retiro São Bento, quanto ao sexo, idade, outras pessoas residentes na casa e algumas observaçóes

\begin{tabular}{|c|c|c|c|c|}
\hline \multicolumn{5}{|c|}{ COMUNIDADE DE SÃO PEDRO } \\
\hline Família & Sexo & Idade & $\begin{array}{c}\text { Outros } \\
\text { moradores } \\
\text { na casa }\end{array}$ & Observaçōes \\
\hline \multirow[t]{2}{*}{1} & M & 83 & \multirow{2}{*}{$\begin{array}{l}01 \text { filho } \\
\text { solteiro, } \\
\text { professor da } \\
\text { escola local }\end{array}$} & \multirow{2}{*}{$\begin{array}{l}1 \text { sobrinha auxilia afazeres domésticos sob } \\
\text { remuneração }\end{array}$} \\
\hline & F & 79 & & \\
\hline \multirow[t]{2}{*}{2} & $\mathrm{M}$ & 68 & \multirow[t]{2}{*}{-} & \multirow[t]{2}{*}{ cuidam de duas netas, de 7 e 9 anos } \\
\hline & $\mathrm{F}$ & 62 & & \\
\hline \multirow[t]{2}{*}{3} & $\mathrm{M}$ & 60 & \multirow{2}{*}{$\begin{array}{l}01 \text { filho } \\
\text { solteiro }\end{array}$} & \multirow[t]{2}{*}{-} \\
\hline & $\mathrm{F}$ & 61 & & \\
\hline \multirow[t]{2}{*}{4} & $\mathrm{M}$ & 92 & \multirow[t]{2}{*}{-} & \multirow[t]{2}{*}{-} \\
\hline & $\mathrm{F}$ & 75 & & \\
\hline \multirow[t]{2}{*}{5} & M & 65 & \multirow{2}{*}{$\begin{array}{l}03 \text { filhos } \\
\text { solteiros }\end{array}$} & \multirow{2}{*}{$\begin{array}{l}\text { Residiu por } 20 \text { anos em Cuiabá e há } 20 \text { retornou } \\
\text { à localidade }\end{array}$} \\
\hline & $\mathrm{F}$ & 61 & & \\
\hline 6 & M & 63 & $\begin{array}{l}03 \text { filhos } \\
\text { solteiros }\end{array}$ & Separado da esposa \\
\hline \multirow[t]{2}{*}{$7^{*}$} & $\mathrm{M}$ & 60 & \multirow{2}{*}{$\begin{array}{l}02 \text { filhas } \\
\text { (pequenas/ } \\
\text { crianças) e } \\
01 \text { neto }\end{array}$} & \multirow{2}{*}{$\begin{array}{l}\text { A sogra mora em outra residência, nos fundos } \\
\text { da propriedade, é aposentada e contribui com a } \\
\text { renda familiar }\end{array}$} \\
\hline & - & - & & \\
\hline 8 & $\mathrm{M}$ & 65 & - & $\begin{array}{l}\text { Separado da esposa há mais de } 20 \text { anos. Conta } \\
\text { com a irmã que mora na localidade }\end{array}$ \\
\hline $\begin{array}{l}\text { Subtotal } \\
\text { entrevistados }\end{array}$ & \multicolumn{4}{|l|}{13} \\
\hline \multicolumn{5}{|c|}{ COMUNIDADE DE RETIRO SÃO BENTO } \\
\hline \multirow[t]{2}{*}{9} & M & 67 & \multirow{2}{*}{$\begin{array}{l}\text { dois filhos e } \\
\text { quatro netos }\end{array}$} & \multirow{2}{*}{$\begin{array}{l}\text { A renda estava comprometida por um empréstimo } \\
\text { bancário feito para custear a plantação }\end{array}$} \\
\hline & $\mathrm{F}$ & 62 & & \\
\hline \multirow[t]{2}{*}{10} & $\mathrm{M}$ & 63 & \multirow[t]{2}{*}{3 filhos } & \multirow{2}{*}{$\begin{array}{l}\text { O senhor é benzedor de plantação e de "criação"/ } \\
\text { animais }\end{array}$} \\
\hline & $\mathrm{F}$ & 60 & & \\
\hline 11 & $\mathrm{~F}$ & 73 & $\begin{array}{l}\text { Mais 9 } \\
\text { pessoas } \\
\text { (as filhas, } \\
\text { um genro } \\
\text { e netos) } \\
\text { distribuídas } \\
\text { em } 2 \text { casas }\end{array}$ & $\begin{array}{l}\text { Viúva há mais de } 10 \text { anos. } \\
\text { Conta com uma família, de mais posses, } \\
\text { da comunidade que traz o dinheiro da } \\
\text { aposentadoria sem cobrar pelo ato }\end{array}$ \\
\hline $\begin{array}{l}\text { Total } \\
\text { entrevistados }\end{array}$ & \multicolumn{4}{|l|}{$18^{* *}$} \\
\hline
\end{tabular}

* Uma idosa não foi entrevistada por estar em viagem em Cuiabá/MT

** Todos os idosos participantes recebiam aposentadoria equivalente a 01 salário mínimo $(\mathrm{R} \$ 465,00)$ na ocasião 
Nota-se que os filhos/filhas solteiros são, na sua maioria, do sexo masculino e residem com os pais, ou próximos a eles, já que, a partir do casamento, a família do filho constrói outra casa próxima à primeira residência para abrigar o novo casal ou parentes. Caso a família tenha mais posses, a nova moradia é construída em outro sitio e o casal fica responsável pela "lida" da terra no local.

Os dados foram coletados por entrevistas gravadas, orientadas por roteiro semiestruturado, bem como pelas conversas "informais" e pela observação da dinâmica social intradoméstica e local, valendo-se do diário de campo para registro e tratados pela técnica da análise temática (VICTORA et al. 2000; MINAYO, 2006). Embora fortemente inspirada no método etnográfico, o estudo caracteriza-se como pesquisa qualitativa em saúde, distinta da etnografia (CAPRARA; LANDIM, 2008).

Os resultados aqui apresentados foram organizados em categorias referentes a dois aspectos do apoio social mobilizados nos momentos críticos expressos localmente como de "precisão": situações de comprometimento da saúde e de outras demandas cotidianas.

Observando os princípios éticos da Resolução 196/96 do Conselho Nacional de Saúde sobre pesquisa com seres humanos, o projeto foi e aprovado pelo Comitê de Ética em Pesquisa do Hospital Universitário Júlio Muller (Protocolo no 523/CEP/HUJM/2008). Os sujeitos são identificados neste texto por Senhor ou Senhora seguido de numeração da família de pertença.

\section{Caracterização do local e dos sujeitos da pesquisa: identidade - compartilhamento e diferenciação}

Os idosos participantes da pesquisa fazem parte de população tipicamente campesina. O campesinato constitui uma categoria social específica dentro da sociedade capitalista (MARQUES, 2004) caracterizado por uma organização social que ora serve aos interesses capitalistas, ora lhes é contraditória.

O modo de vida ${ }^{1}$ camponês envolve um conjunto de práticas, valores e significados que é negociado e marcado por um contexto (HELLER, 1977; ALMEIDA FILHO, 2004; MARQUES, 2004) e pela tradição caracterizada pela sociabilidade territorializada, preferencialmente em escala local, informada pelo sentimento de pertencimento ao lugar. Esse tradicionalismo se realiza por meio da transmissão e da reprodução entre gerações de práticas e valores, que 
apresentam mudanças num ritmo mais lento em contraste com aquele colocado/ imposto pela modernidade. Como em outras populações tradicionais (CRUZ, ARAÚJO; ARAÚJO, 2008), a tradição campesina é, em parte, mantida pelos mais velhos de uma comunidade, constituindo-se em referência aos conhecimentos da história local, ao manejo com a terra e à criação dos filhos - à reprodução social e cultural, portanto.

Assim, o compartilhamento de um conjunto de características molda o modo de ser do povo de Joselândia, mostrando haver um domínio comum, homogêneo nessa identidade. Contudo, simultaneamente a esse plano mais genérico, verifica-se uma diferenciação ao refinarmos as variáveis de análise para as duas comunidades enfocadas neste artigo - São Pedro e Retiro São Bento.

Os moradores da comunidade de São Pedro usufruem de melhores condições de moradia e de saneamento básico, quando comparados aos moradores da comunidade do Retiro São Bento. As diferenças não se dão apenas nesse âmbito: os vínculos estabelecidos entre os membros das famílias se modificam à medida que a maneira de ajudar em casa também se modifica. Nota-se que os filhos têm papel importante na vida dos pais, no sentido de ajudar na melhoria da qualidade de vida, e que estes retribuem a ajuda com gratidão e afeto, sedimentando a noção de reciprocidade. Nesse caso, subjaz uma ordem com distribuição diferencial de valores que orienta os sujeitos em situação, e que pode ser compreendida pela noção de hierarquia (DUMONT, 1985). Essa lógica hierárquica, pela qual há preeminência do coletivo em detrimento do individual expresso pela solidariedade familiar, é comum entre grupos camponeses e, como aponta DUARTE (1995), assemelha-se ao verificado em segmentos populares urbanizados.

Esse modo de vida do homem pantaneiro envolve um conjunto de símbolos com os quais ele convive, quais sejam: o ciclo das águas e o plantio, a terra (enquanto geradora de alimentos e remédios), e a família como o foco das atençôes, primeiro como filhos e depois como pais e avós. É oportuno lembrar que tais papéis pautam-se por interesses coletivos e são adaptativos à reprodução social do grupamento agrícola cuja sobrevivência é razão direta do emprego da força familiar na lavoura e tarefas domésticas "de apoio" (ROZEMBERG; MINAYO, 2001 - destaque nosso).

As diferenças entre as comunidades parecem refletir o peso das estruturas na atual conformação do universo rural, onde o que subjaz àquela classificação, o que 
torna uma comunidade mais "forte" ou "fraca", refere-se à sua inserção em um

projeto de crescimento econômico não desvinculado de nuances histórico e políticos.

Comparativamente, os idosos da comunidade Retiro São Bento a definem por mais "fraca" ao expressar que "Lá, eles [comunidade São Pedro] são forte. Nós é fraco, não tem condições de nada, a gente fica muito longe”. Em Retiro São Bento, além do alto grau de dependência dos produtos da terra, orientada pela agricultura familiar, a distância dos serviços engendra desigualdades de acesso. Diante disso, mais se faz necessária a coesão familiar como apoio estratégico ao enfrentamento das demandas cotidianas (e, por vezes, como estratégia de sobrevivência).

A comunidade São Pedro foi contemplada com importantes apoios institucionais locais, imprimindo-lhe característica de "vilarejo rural", contando com escola até segundo grau, unidade básica de saúde, cartório de registro civil e inúmeros bares e mercearias que, para além do abastecimento, fornecem-lhes produtos alimentares, diversos materiais de higiene e remédios. Soma-se a isso, ainda, a disponibilidade diferenciada de transporte para a cidade, aumentando as possibilidades de inserção dos moradores locais no mercado de trabalho e, relativizando a sua dependência da terra, sendo essa relação em alguns casos invertida dando lugar à complementaridade.

Situação semelhante foi observada por Heck e Langdon (2002) no estudo sobre comunidade rural no sul do Brasil, que aponta que aquelas famílias vivem uma contradição entre a necessidade de pensar no futuro dos filhos e a sua utilização na lida com a terra, já que estes são um investimento que deve retornar à propriedade como força de trabalho sem remuneração, situação esta relacionada também com a redução da área das propriedades.

As transformações locais aparecem sutilmente nos relatos dos idosos ao explorarmos um importante papel social por eles desempenhado, em especial em populaçôes com fortes traços tradicionais: o de lembrar.

Quando comparam a época da vida de sua juventude com a atual, a da velhice, as opiniōes divergem: alguns dizem que o tempo passado era melhor porque "a terra dava mais, colhia mais do que hoje" (Senhor H9), enquanto que, para outros, plantar hoje é mais fácil porque “... quando eu tava no tempo de criança era tudo mais difícil. Nós cortava árvore no machado [...]"(Senhor H3). Nesse sentido, referem à facilidade de obtenção de produtos: "Hoje tá bom. Hoje tem crédito. Se você tá precisando de café, um guaraná [em pó], um açúcar, tem crédito. Antes 
não. Agora, você paga depois" (Senhor H6). Porém há quem diga que no passado era melhor: "Naquele tempo era mais fácil porque os mascates traziam tudo na porta quando tava cheio, e na seca ia na beira do rio com um saco de arroz, voltava cheio de mantimentos. Hoje é só no dinheiro e num compra nada" (Senhora M3).

Esses excertos parecem aludir ao tempo passado, em que havia uma união que foi perdida, aproximando-se do que Candido (1979) chamou de saudosismo transfigurador, explicando manifestar-se, sobretudo nos mais velhos que tiveram contato com a vida tradicional e podem compará-la com o presente.

Nessa situação, são comparadas as atuais condições de vida com as antigas, as modernas relações humanas com as do passado, sendo que as primeiras remetem principalmente a três tópicos: abundância, solidariedade e sabedoria. Mostram também transformaçôes econômicas e seus reflexos locais com desproporcionalidade entre a oferta, a disponibilidade de mercadorias e o poder aquisitivo, sendo comum o acesso ocorrer pela estratégia do crédito, decorrente da exiguidade dos recursos e tendo como consequência possível endividamento.

Tal idealização é vista, também, por Ferreira (2006), como mecanismo que obscurece a consciência das realidades do presente, em um passado matizado por noções de felicidade e realização. Certamente, cada época tem as suas peculiaridades que são classificadas de boas ou más, em conformidade com os valores de quem as avalia.

Nas suas reminiscências, as atividades que desempenhavam quando jovens são relatadas com sinais de cansaço, como um tempo caracterizado pela luta diária para garantir a sobrevivência e a criação dos filhos e pela fixidez na região ou em comunidades da redondeza, o que permitia o trabalho com pequena lavoura e criação de animais. Cada informante relatou sua história pela dificuldade de sobreviver na região:

[...] sou residente daqui. Meus pais e meus avós não. Eles vieram de fora. Aí eu tô aqui até a idade que eu tô hoje... É, eles estavam andando e viram esse lugar, acharam bom e ficaram. Quando eu nasci eles já eram morador antigo daqui e minha vida desde pequeno é na roça - desde 12 eu luto no serviço da roça e da lavoura... (Senhor H4)

Ressalta-se que, os idosos detêm o saber-fazer do cultivo agrícola, que é transmitido tradicionalmente às gerações posteriores, sendo este também um dos seus papéis em comunidades campesinas, conferindo-lhe "respeito", pois esse conhecimento é visto como sinônimo de sabedoria entre os demais 
integrantes da família e da comunidade, facultando-lhes participar das decisões

familiares e comunitárias. $O$ fato dos filhos permanecerem na terra, mesmo com as dificuldades do trabalho na roça, aponta para a falta de perspectiva da inserção destes em outras atividades na cidade ou de criação de ligação cultural e afetiva com as raízes agrícolas. Sobre esse aspecto, há diferenças quando se trata de homens e mulheres, já que é comum estas últimas se inserirem como domésticas na cidade - ocupação em que, em geral, a escolaridade não tem peso significativo. Em consequência, como também verificado no estudo de Heck e Langdon (2002), observa-se maior número de homens solteiros na comunidade, preteridos pelas mulheres que trabalham na cidade como recusa às dificuldades impostas pelo contexto rural, ainda que este detenha elementos positivos em relação aos contextos urbanizados.

\section{O idoso campesino e o apoio social na "precisão"}

Diante das especificidades das condições de vida dessa população em território rural, estratégias singulares são empreendidas na sua reprodução biológica e social e, para tanto, mobilizam-se recursos materiais e imateriais de uma rede de apoio social com conformação e dinâmica igualmente peculiares. Tais apoios variam quanto aos seus tipos e fontes, podem ser mais visíveis ou mais tênues - porém não menos importantes para a vida local do campesino idoso-, sendo requeridos ao enfrentamento de situações cotidianas críticas, expressas nativamente como "de precisão". Tais situações decorrem em grande parte das condições históricas (não incomum às comunidades rurais) que provocam a "fragilidade ${ }^{2} \mathrm{da}$ vida social e coletiva na sua organização, sistemas de valores e regulações” (HERZLICH, 2005, p.200), ainda que ela se dê com resistências (PIGNATTI; CASTRO, 2010).

Os apoios se dão em vários aspectos da vida, mas em nenhum deles com tanto vigor quanto no que tange à saúde, cujos tipos mobilizados são influenciados pelo modo de vida rural e moldam significativamente suas representações sobre saúde, doença, trabalho. Assim, os idosos entrevistados têm, geralmente, uma visão de que desfrutam de muita saúde, pois "ah, eu nunca fico doente, não me lembro de ter ficado doente" (senhor H4) ou "nem lembro quando foi a última vez que fiquei doente" (senhor H6).

Alguns depoimentos mostram, ainda, qual é a visão de doença: "Não lembro de ter ficado internada. Nunca internei nem fiquei na cama doente" (senhora M6). 
Pelo fato de o tipo de trabalho nessa comunidade rural ser o trato com a roça e os animais, tanto idosos quanto adultos valem-se de esforço físico para a garantia da sobrevivência, o que faz com que uma doença seja considerada como tal se limitar ou impedir essas atividades cotidianas. Tal conceito aproxima-se daquele verificado em estudos com segmentos populares (BOLTANSKI, 1979) pautado pela relação mantida com o corpo e o trabalho.

Há relatos sobre perturbações menores, não classificadas como doença propriamente, como:

às vezes tem uma gripe, arca caída, mas logo cura. Não tem problema, porque tem que trabalhar, né. Não é uma gripe que me derruba" (senhor H5); ou "doença mesmo não. Só arca caída, um quebrante, uma gripe, mas nunca fiquei doente. Nunca deixei de trabalhar (senhor H5).

Nesses casos, assemelham-se ao "mal estar" (QUEIROZ, 1991) ou a "problemas de saúde" (BARSAGLINI, 1999) diante dos quais, aguarda-se a sua solução natural ou recorre-se aos sistemas terapêuticos populares e religiosos que são amiúde mobilizados como os benzimentos e os chás preparados por cônjuge ou filho. Assim, o parâmetro da doença refere-se ao desempenho social, incidindo nas e expresso pelas atividades cotidianas, com destaque para o trabalho, que possibilita o cumprimento dos compromissos e papéis sociais.

Quanto aos problemas de saúde referidos pelos idosos estão aqueles decorrentes ou não do envelhecimento, e que podem ser prevenidos ou amenizados pela atuação dos serviços oficiais de saúde. São eles: queda; fratura de fêmur, hipertensão arterial, acidente vascular encefálico ("derrame"); hanseníase (em tratamento finalizado ou em andamento, mas ambos com sequelas). O comprometimento da mobilidade e a tonteira, comuns no envelhecimento, aliado às características do ambiente e das atividades tipicamente rurais, podem colocar o idoso na situação de fragilidade corporal, sendo que esta sofre interferência, como lembra HERZLICH (2005), da fragilidade social.

No caso da hanseníase, há que se considerar a importância de representações sobre saúde e doença, cura, medicamentos, todas cotejadas pelas sensaçõos corporais "estranhas" que perturbam a força demandada cotidianamente nas atividades rurais, expressas no excerto: "Eu acho que esse remédio [para hanseníase] não cura, porque eu tomo ele e fico fraco. Sem ele eu fico bem. Remédio tem que deixar a gente bem” (H2). Tais parâmetros podem influenciar o abandono do tratamento, e não se colocam em um plano individual, mas 
coletivo e relacional, devido ao seu caráter sócio cultural, ou seja, o adoecido se insere em um contexto histórico do qual recebe informaçôes (sobre saúde, doença etc.) que podem, em parte, influenciar seus comportamentos quanto às prescriçôes. É o caso de uma ideia dominante e oposta à saúde, a de que o medicamento é consumido em situações de doença (STIMSON, 1974) o que se observa, para além da hanseníase, em outras enfermidades crônicas que impõem o seu uso (prolongado ou contínuo).

A desvantagem do acesso aos serviços de saúde também pode ser um fator fragilizador dos idosos residentes em área rural, como visto por Travassos \& Viacava (2007), sendo que, no caso em questão, a estrutura e a dinâmica da rede social podem abrandar a vulnerabilidade social, onde a carência de apoio formal se faz mais presente. A redução dessas desvantagens implica melhorar a oferta de serviços para a população rural, além de organizá-los de modo a atender às especificidades territoriais, culturais e sociais do referido grupo.

A precariedade de estrutura local de assistência à saúde voltada à vigilância de agravos, prevenção de doenças e promoção da saúde se estende às intervenções de urgência. Nesse último caso, os relatos informam que é preciso fretar o avião para chegar até a cidade que dispõe do recurso necessário (em geral, Cuiabá, a 100 quilômetros de distância) o mais depressa possível, ao custo de $\mathrm{R} \$ 400,00$, ou seja, quase todo o salário (mínimo/R $\$ 465,00$ ) do aposentado.

Ao mesmo tempo, as redes de apoio se ampliam, no caso do cuidado com as doenças, pela ajuda dos parentes que residem em Cuiabá (as oito famílias de São Pedro têm algum vínculo parental em Cuiabá), e a partir daí outras redes de apoio são estabelecidas para o acesso aos serviços de saúde. Essa elasticidade/plasticidade da rede para o apoio coaduna-se à noção de territorialidade pela sua conotação material e social (HAESBERT, 2005). Se por um lado ela se estabelece no território de Joselândia (local de moradia e atividades cotidianas dos sujeitos), por outro lado os laços de parentesco, amizades e serviços disponibilizados na capital Cuiabá, tecem uma rede ampliada de apoio - para os que têm conhecidos, parentes ou até mesmo funcionários públicos inseridos nos serviços ou vereadores, deputados, radialistas. As redes submersas, baseadas em códigos culturais e solidariedades construídas no cotidiano, podem tornar-se redes com visibilidade (articulações políticas) quando esses pequenos grupos que compartilham de uma identidade coletiva se mobilizam para interferir nas políticas públicas (MELUCCI, 1989). 
Essa aproximação rural/urbano, no entanto, não destrói as particularidades de cada polo, mesmo quando desaparecem as diferenças no acesso aos bens materiais e de serviços, como já ocorre em algumas áreas mais desenvolvidas do país (CARNEIRO, 2005; WANDERLEY, 2001). Há uma permeabilidade das fronteiras destes "polos", havendo fluidez e influências recíprocas, mas com manutenção das respectivas identidades nesse território.

Da mesma forma, a dinâmica rural local mostra-se afetada pelas características do contexto mais amplo no qual se insere. Assim é que, sob o ponto de vista biológico, as alterações relacionadas à idade ocorrem praticamente em todas as partes do corpo, trazendo diversas mudanças funcionais ao organismo do idoso (BUENO et al., 2008). O trabalho rural, por exigir demasiado esforço físico, faz com que o desgaste corporal ocorra precocemente. Todavia, o ritmo impresso pelo emprego da força familiar na lavoura e pelas tarefas domésticas de apoio (ROZEMBERG; MINAYO, 2001) poupa os mais velhos das tarefas mais pesadas, que passam a ser realizadas paulatinamente pelos mais jovens, ainda que de maneira mais focalizada e menos intensa em decorrência das restriçôes espaciais ao uso da terra, bem como da migração da mão de obra familiar em busca de alternativas laborais do contexto urbano.

Tanto é que a exposição às variações ambientais, como sol, chuva, vento e umidade (cheias), a falta de saneamento básico e a proximidade com a RPPN (focos naturais) tornam essa população vulnerável às inúmeras doenças transmissíveis (como as diarreias), cujos sobreviventes da primeira infância parecem desenvolver algumas resistências e apresentam sintomas inespecíficos no decorrer da vida adulta (SILVA, 2007).

Assim, percebe-se, no modo de relacionamento daquelas pessoas, que a proximidade entre os atores sociais se mescla, muitas vezes, com atributos de parentesco ou de amizade no apoio, numa relação de afeto e de ajuda aos problemas do cotidiano. que extrapolam os limites físicos espaciais locais. Laços de solidariedade, trocas e obrigações parecem reger esse apoio, e, como apontou Stephens (2008), podem ampliar o senso de comunidade e coesão. São expressões de uma hierarquia em que o bem coletivo sobrepõe-se ao individual, como exemplarmente discutido por Duarte (1986) em segmentos populares, mas que parece mais fortemente operar em comunidades rurais. Como ilustra o fragmento de relato: 
[...] quando adoecia, passava mal, aí pegava a vaquinha que tinha, vendia. Esse tempo não tinha emprego, aí meu pai arrumava dinheiro. Enquanto meu pai era vivo ainda tinha esperança, ele ajudava, era alegre, ajudava eu. Aí minha mãe, coitada, era doente. Depois que papai morreu, minha mãe era doente e ela veio morar com a gente, aí meu irmão também ajudava - esse que tá aí. O que morreu pescava, ajudava, coitado. No Natal dava um peixe, um pedaço... (Senhora M2)

O parentesco, a amizade e a identidade interligam as pessoas em relações de reciprocidade por diversos motivos. Chama ainda a atenção o papel dos vínculos para a manutenção da saúde. A reciprocidade envolve um sistema de troca, caracterizando a economia do dom no sentido da dádiva que pressupõe o dar, receber e retribuir bens e serviços, materiais e simbólicos (MAUSS, 2003). O caráter voluntário dessa circulação é aparentemente livre e gratuito, e, no entanto, obrigatório e interessado porque perpassado de sentidos morais, afirma o autor em seu clássico ensaio sobre o tema, publicado em 1950. As trocas, no entanto, regem-se por normas contratuais tácitas por que

Se coisas são dadas e retribuídas, é porque se dão e se retribuem 'respeito' - podemos dizer igualmente 'cortesias'. Mas é porque as pessoas se dão, ao dar e, se as pessoas se dão, é porque se 'devem' - elas e seus bens - aos outros (grifo do autor - MAUSS, 2003, pag. 263).

É oportuna essa compreensão para os apoios dados e recebidos, ressaltandose sempre a circulação imediata, circunstancial ou não para além da sua dimensão material.

No estudo em questão, o apoio social toma diversas características, abarcando prestações e contraprestações de ações generosas recompensadas nas relações de parentesco, de amizade ou mesmo de comércio.

\section{O campesino idoso e o apoio social: demandando e oferecendo apoio}

De modo geral, se, na ausência ou insuficiência das fontes de apoio formal, os recursos informais são mais intensamente mobilizados no enfrentamento das situações cotidianas, no meio rural, a família, como fonte de colaboração "natural", mais se faz presente e necessária, reforçando a centralidade da unidade doméstica e familiar própria das comunidades rurais. Contudo, também a sua estrutura e dinâmica são permeáveis às transformações contextuais mais amplas que levaram as novas geraçôes a buscar melhores oportunidades de trabalho e 
condições de vida no meio urbano. A lógica dessa população campesina e da agricultura familiar tem sido modificada pela mercantilização das relaçoos de troca, moldando o território em seus vários aspectos e comprimindo ou favorecendo a extensão das redes de apoio.

Assim, a presença da família é central como fonte de apoio, de modo que cada componente ajuda como pode a melhorar a vida do outro, em especial na hora da "precisão", variando o tipo de apoio. Alguns responderam "Ninguém me ajuda, só os filhos que trabalham na roça, senão num tem o que comer. Ajuda em alguma coisa da casa, mas fora isso, ninguém faz nada" (Senhor H9); sugerindo uma naturalização da ajuda no âmbito familiar - obrigação inerente às normas familiares, que permeia as relações de reciprocidade adquiridas enquanto valor moral em comunidade campesina.

Nota-se que os filhos sempre ajudam, seja com bens (gêneros alimentícios, medicamentos, quitação de uma dívida, dinheiro) ou prestação de serviços (como mão de obra na roça ou pagando alguépara esse serviço, transportando os idosos para a cidade, levando-os a um serviço de saúde), como relatam:

É minha filha que Deus mandou pra mim. Graças a Deus minha filha compra meus remédios. Ela manda com quem sempre vem pra cá. Não deixa faltar os remédios - porque meus remédios, tem que tomar certo. E algum remédio caseiro. E corto a gordura e evito bastante, assim, o sal e a gordura. (Senhora M2)

Percebe-se que é significativa a ajuda dos filhos no plano econômico/material, tanto com o próprio trabalho quanto com dinheiro. Nas famílias de São Pedro, observou-se que há uma diversificação nas atividades realizadas pelos filhos dos idosos, além daquelas da roça, sendo que alguns deles passaram a exercer atividades como professores na escola local ou como comerciantes, garantindo assim outra fonte de renda para suas famílias. Isso mostra a insuficiência da provisão das necessidades pelo uso exclusivo da terra, impelindo os moradores a novas inserções no processo de reprodução material e, de certa forma, refletindo mudanças contextuais/ambientais mais amplas. $\mathrm{O}$ acesso à aposentadoria (lembrando que todos os idosos entrevistados recebem o benefício) vem como alento à situação, comportando positividade, mas também contradições, fato também observado por Cabral (1986) com trabalhadores rurais na Paraíba, que passaram a ter direitos legalmente assegurados, mudando as relações de trabalho que, até então, eram de dependência. 
Na busca de bens e de serviços (de saúde, para exames e tratamentos; bancários para recebimento do benefício; comercial para aquisição de roupas, calçados, alimentos, medicamentos, etc.), a relação com a cidade (cuja referência é Cuiabál capital e não Barão de Melgaço) cria nos idosos a necessidade de ter um lugar para se hospedar, que pode ser a casa própria ou a de um filho, de algum parente ou conhecido. Assim, a rede de apoio social mobilizada expande a noção de território para a de territorialidade.

Enfim, a visão universalista com representações da velhice enraizadas nas ideias de deterioração e perda deve ser relativizada (UCHÔA, 2003) já que a condição de idoso pode carregar contradiçōes e pode gerar sentimentos ambíguos quando remete à não-produtividade e à aposentadoria. Nas famílias estudadas, por exemplo, o fato de o idoso ser aposentado pode constituir um fator positivo, conferindo-lhe uma posição de prestígio e reciprocidade na relação familiar, pois em muitos casos representam a principal (senão a única) fonte de renda, embora para os moradores do Retiro São Bento, parte dela é gasta para o deslocamento para receber o próprio benefício. Ao mesmo tempo em que necessitam de cuidado e apoio, passam, nesse caso, a ofertá-lo/retribuí-lo.

\section{Considerações finais}

O modo de vida camponês, no contexto do território rural do Distrito de Joselandia, baseia-se na produção agrícola familiar, tendo como prática a utilização da força de trabalho dos idosos, filhos e netos, para os quais o cultivo da terra tem significado na reprodução material e simbólica do grupo, marcado pela tensão e permeabilidade entre o rural/urbano e entre as restrições de uso do espaço para a reprodução do seu modo de vida por se localizar no entorno de área de preservação ambiental. Não obstante, os idosos desempenham um papel fundamental na manutenção dos valores e tradição, cotejados pelo pertencimento e identidade com o lugar, ou seja, na territorialidade (HELLER, 1977; HEIDRICH, 1998; ALMEIDA FILHO, 2004; MARQUES, 2004; WOORTMANN, 2004; SANTOS, 2006; CRUZ; ARAÚJO; ARAÚJO, 2008).

De modo geral, os moradores idosos entrevistados não desvinculam o cuidado com a terra das dimensões física e simbólica, pois ela significa o lugar onde vivem e de onde tiram o sustento de sua família, que, por sua vez, sintetiza todo o sentido 
de sua existência. Por isso, a expressão "filho da terra" é tão evidente nas suas falas, sendo oportuna para a sua compreensão a noção de território, que, além da dimensão material, incorpora a dimensão simbólica, confluindo do plano político para o cultural, ou seja, das fronteiras dos povos aos limites do corpo e do afeto das pessoas (BARCELLOS et al., 2008). Esses territórios simbólicos, culturalmente carregados, são marcados por vizinhança, intimidade, emoção, cooperação e socialização com base na contiguidade, configurando relações e vínculos que atualmente vêm sendo abordados cientificamente sob a denominação de redes (SCHERER-WARREN, 2006), e que, ainda que se aproximem da noção de apoio, possuem especificidades que extrapolam os limites deste texto.

Nas duas comunidades estudadas, a autoclassificação em "fracos" e "fortes" é emblemática, comportando uma diferença no respectivo potencial político e econômico expresso por mais recursos oficiais/instituiçôes, constituindo-se em modalidades importantes de apoio formal.

Com a expansão do acesso às aposentadorias, o idoso, em muitos casos, passou a ser uma importante fonte de apoio, desempenhando, em certo grau, o papel de cuidador (da família). A família é chefiada pelos idosos, que são responsáveis também pela manutenção e pelo cuidado dos filhos (adultos e adolescentes) e netos. É comum a renda da aposentadoria manter a casa, suprindo as necessidades que a terra não consegue suprir, tais como roupas, calçados, remédios e até mesmo alimentos complementares ou essenciais, quando o resultado da lavoura não é satisfatório. $\mathrm{O}$ dinheiro da aposentadoria é fundamental para a sobrevivência familiar e da economia local, cujo já pequeno montante (em geral composto por salários mínimos) é diminuído/comprimido ainda mais pela fragilidade institucional local. Tais dificuldades expõem a desigualdade e a vulnerabilidade dos idosos e mostram, assim, uma faceta da sua dependência tutelada pelo Estado - situação que transcende particularismos locais para se aplicar a muitas outras realidades na sociedade contemporânea.

A família desempenha um papel importante na provisão de cuidado informal para com os seus membros (SERAPIONE, 2009), o qual ocorre, em geral e em grande parte, no ambiente doméstico. Ocorre que ela não está imune ao contexto. Ou seja, políticas públicas específicas podem afetar a capacidade e formas de prover cuidado (quem, como e quando cuidar; remunerado ou não), mas também o tipo de problema que demanda cuidado pode requerer arranjos 
na sua estrutura e funcionamento, tais como agregar parentes e reprogramar

atividades cotidianas. Deve-se destacar, contudo, que admitir a relevância e a centralidade da família não autoriza a responsabilizá-la pelo cuidado, pois o Estado também deve responder por ele não apenas definindo a família como alvo das políticas, mas cabendo talvez desindividualizar o olhar, deslocando-o para o plano coletivo dos determinantes e mediadores da sua fragilização, ou seja, a família e seus vínculos territoriais histórica e socialmente marcados.

\section{Referências}

ADAM, P.; HERZLICH, C. Sociologia da doença e da medicina. São Paulo: Edusc, 2001. p. 49-68.

ALMEIDA FILHO, N. Modelos de determinação social das doenças crônicas nãotransmissíveis. Ciência e Saúde Coletiva. Rio de Janeiro, v. 9, n. 4, p. 865-884, 2004.

BARCELLOS, C. et al (Orgs). Território, ambiente e saúde. Rio de Janeiro: Fiocruz, 2008. BARSAGLINI, R.A. Representaçôes e práticas de saúde da população do Distrito de Nossa Senhora da Guia - CuiabálMato Grosso. Dissertação (Mestrado em Saúde e Ambiente)Instituto de Saúde Coletiva, Universidade Federal de Mato Grosso, Cuiabá, 1999.

BOLTANSKI, L. As classes sociais e o corpo. Rio de Janeiro: Graal, 1979. 191 p.

BRASIL. Ministério do Meio Ambiente. Projeto Nova Cartografia Social dos Povos e comunidades tradicionais do Brasil. Fascículo 10. Povoado Pantaneiro de Joselândia. Brasilia, DF, abril 2007. 4p.

BUENO, J.M. et al. Avaliaçãoo Nutricional e prevalência de doenças crônicas não transmissíveis em idosos pertencentes a um programa assistencial. Ciência e Saúde Coletiva. Rio de Janeiro, v. 13, n. 4, jul/ago. 2008. p. 1237-1246.

CABRAL, B.E.S.L. De trabalhadores a aposentados do Prorural. As contradições da política social e a concessão tardia de direitos. Dissertação (Mestrado em Sociologia) - Universidade Federal da Paraíba, João Pessoa,1986.

CÂNDIDO, A. Os parceiros do Rio Bonito. São Paulo: Duas Cidades, 1979.

CANESQUI, A.M.; BARSAGLINI, R. A. Apoio social e saúde: pontos de vista das ciências sociais e humanas. Rev. Ciência e Saúde Coletiva. 2010. Disponível em: http:// WWW.cienciaesaudecoletiva.com.br/artigos/artigo_int.php?ide_artigo=5745. Acesso em: 26/01/2011.

CAPRARA, A.; LANDIM, L.P. Etnografia: uso, potencialidades e limites na pesquisa em saúde. Interface - Comunic., Saúde, Educ., Botucatu, v. 12, n. 25, jun. 2008.p.363-376.

CARNEIRO, M.J. Apresentação. In: MOREIRA, R.J. (org.) Identidades sociais: ruralidades no Brasil contemporâneo. Rio de Janeiro: DPeA, 2005. p. 7-13. 
CRUZ, I.B.M.; ARAÚJO, M.C.P.; ARAÚJO, L.M.A. O idoso e a transmissão do conhecimento oral em populações tradicionais. In: CRUZ, I.B.M.; GOMES, L. Envelhecimento dos povos tradicionais brasileiros: perspectivas e desafios. Brasília: Universa, 2008. p. 97-130.

DEBERT, G.G. A invenção da terceira idade e a rearticulação de formas de consumo e demandas políticas. Trabalho apresentado no GT Cultura e Política da ANPOCS. 1996 <http://www. anpocs.org.br/portal/publicacoes/rbcs_00_34/rbcs34_03>. Acesso em: 20/05/2011.

A antropologia e o estudo dos grupos e das categorias de idade. In: BARROS, M.M.L. (Org.). Velhice ou terceira idade? Estudos antropológicos sobre identidade, memória e política. Rio de Janeiro: Edit. FGV, 2006. p. 49-67.

DUARTE, L.F. Da vida nervosa nas classes trabalhadoras urbanas. Rio de Janeiro: Zahar, 1986. 290p.

DUMONT, L. O individualismo: uma perspectiva antropológica da ideologia moderna. Rio de Janeiro: Rocco, 1985.

FERREIRA, M.L.M. Memória e velhice: do lugar da lembrança. In: BARROS, M.M.L. (Org.). Velhice ou terceira idade? Estudos antropológicos sobre identidade, memória e política. Rio de Janeiro: FGV, 2006. p. 207-222.

HAESBAERT, R. Da desterritorialização à multiterritorialidade. São Paulo: Anais do X Encontro de Geógrafos da América Latina, 2005.

HEIDRICH, A.L. Fundamentos da Formação do Território Moderno. Boletim Gaúcho de Geografia, no 23, AGB - Seção Porto Alegre, 1998.

- Território, integração socioespacial, região, fragmentação e exclusão social. In:

RIBAS, A.D.; SPOSITO, E.S.; SAQUET, M.A. (Org.). Território e desenvolvimento: diferentes abordagens. Francisco Beltrão: Unioeste, 2004, v. único, p. 37-66.

HECK, R.M.; LANGDON, E.J.M. Envelhecimento, relaçôes de gênero e o papel das mulheres na organização da vida em uma comunidade rural. In: MINAYO, M.C.S.; COIMBRAJR, C.E.A. (Org.). Antropologia, saúde e envelhecimento. Rio de Janeiro: Fiocruz, 2002, p. 129-51.

HELLER, A. Sociologia de la vida cotidiana. Barcelona: Península, 1977.

HERZLICH, C. Fragilidade da vida e desenvolvimento das ciências sociais no campo da saúde. Physis: Rev. Saúde Coletiva, Rio de Janeiro, v.15, n. 2, p. 193-203, 2005.

INSTITUTO BRASILEIRO DE GEOGRAFIA E ESTATÍSTICA 2000. Censo Demográfico - Mato Grosso. IBGE, Rio de Janeiro, 2000.

MALDI, D. De confederados a bárbaros: a representação da territorialidade e da fronteira indígenas nos séculos XVIII e XIX. Rev. Antropol., São Paulo, v. 40, n. 2, 1997. Disponível em:<http://www.scielo.br/scielo.php?script=sci_arttextepid=S003477011997000200006 elng=ptenrm=iso $>$. Acesso em: 14 jun 2007 Pré-publicação. 
MARQUES, A.I.M. Lugar do modo de vida tradicional na modernidade. In: OLIVEIRA,AU; MARQUES, MIM (orgs.). O campo no século XXI: território de vida, de luta e de construção da justiça social. São Paulo: Paz e Terra, 2004.

MAUSS, M. Ensaio sobre a dádiva. Lisboa: Ediçōes 70, 2003.

MINAYO, M.C.S.; COIMBRAJR, C.E.A. (Org.). Antropologia, saúde e envelhecimento. Rio de Janeiro: Fiocruz, 2002.

MELUCCI, A. Um objeto para os movimentos sociais. Lua Nova, n. 17, jun. 1989.

PIGNATTI, M.G (coord.) Subprojeto 19: Vigilância e Promoção de saúde de populações do Entorno da RPPN-SESC Pantanal - MT. Cuiabá: Relatório final de Pesquisa, PELD/ CNPQ/UFMT- 2003-2010. Biblioteca ISC/UFMT, 2011.

PIGNATTI, M.G.; CASTRO, S.P. A Fragilidade/resistência da vida humana em comunidades rurais do Pantanal Matogrossense - MT- Brasil. Rio de Janeiro: Revista de Ciência e Saúde Coletiva, v. 15, sup. 2, out 2010. p. 3221-3232.

QUEIROZ, M.I.P. de. O campesinato Brasileiro: ensaios sobre civilização e grupos rústicos no Brasil. Petrópolis: Vozes, 1973.

. Cultura, sociedade rural, sociedade urbana: ensaios. Rio de Janeiro: Livros Técnicos e Científicos, 1978.

ROZEMBERG, B.; MINAYO, M.C.S. A experiência complexa e os olhares reducionistas. Ciência e Saúde Coletiva, v. 6, n. 1, p. 115-23, 2001.

SENA, G.D. Territorialidade e apoio social em saúde dos idosos em comunidades do Pantanal matogrossense. Dissertação (Mestrado em Saúde Coletiva) - Instituto de Saúde Coletiva, Universidade Federal de Mato Grosso, Cuiabá, 2009.

SANTOS, M. Território: globalização e fragmentação. São Paulo: Hucitec, 2006.

SERAPIONI, M. O papel da família e das redes primárias na reestruturação das políticas sociais. Ciência e Saúde Coletiva, Rio de Janeiro, 2009. Disponível em: <http://www.scielo. br/scielo>. Acesso em: 16 dez. 2009.

SHNEIDER, S. A abordagem territorial do desenvolvimento rural e suas articulações externas. Porto Alegre: Sociologias, ano 6, n.11, jan-jun, p. 88-125, 2004.

SCHERER-WARREN, I. Das mobilizaçōes às redes de movimentos sociais. Sociedade e Estado, Brasília, v. 21, n.1, p. 109-130, jan-abr. 2006.

SILVA, E.A. Água de consumo humano: escassez na abundância e contaminação microbiológica nos períodos de cheia e seca Pantanal de MT. Dissertação (Mestrado em Saúde Coletiva) Instituto de Saúde Coletiva, Universidade Federal de Mato Grosso, Cuiabá, 2007.

STEPHENS, C. Social Capital in its place: using social theory to understand social capital and inequalities in health. Soc.Sci. Med., v. 66, n. 2, p. 117-1184, 2008.

STIMSON, G.V. Obeying doctor's orders: a view from the other side. Social Science Medicine, v. 8, p. 97-104, 1974. 
TRAVASSOS, C.; VIACAVA, F. Acesso e uso de serviços de saúde em idosos residentes em áreas rurais, Brasil, 1998 e 2003. Cad. Saúde Pública, Rio de Janeiro, v. 23, n. 10, p. 2490 2502, out 2007.

VERAS, R. Fórum. Envelhecimento populacional e as informaçôes de saúde do PNAD: demandas e desafios contemporâneos. Introdução. Cad. Saúde Pública, Rio de Janeiro, v. 23, n. 10, out. 2007. Disponível em <http://www.scielo.br/scielo.php?script=sci_ arttextepid $=$ S0102-311X2007001000020 elng=ptenrm =iso $>$. acessos em 09 mar. 2011. doi: 10.1590/S0102-311X2007001000020.

VÍCTORA, C.G.; KNAUTH, D.R.; HASSEN, M.N. Pesquisa qualitativa em saúde: uma introdução ao tema. Porto Alegre: Porto, 2000. 132p.

WANDERLEY, M.N.B. A ruralidade no Brasil moderno. In: GIARRACCA, N. (Org.). Una nueva realidad en América Latina. Buenos Aires: Consejo Latinoamericano de Ciencias Sociales, 2001. p. 31-44.

WOORTMANN, E.F. O Saber tradicional camponês e inovações. In: OLIVEIRA, A.U.; MARQUES, M.I.M. (Orgs.). O campo no século XXI: território de vida, de luta e de construção da justiça social. São Paulo: Paz e Terra, 2004.

UCHÔA, E. Contribuições da antropologia para uma abordagem das questões relativas à saúde do idoso. Cad. Saúde Pública [periódico na Internet]. 2003 Jun [citado 2009 Out 15] ; 19(3):849-853. Disponível em: http://www.scielo.br/scielo.php?script=sci_arttextepid=S 010211X2003000300017elng=pt. doi: 10.1590/S0102-311X2003000300017.

\section{Notas}

${ }^{1}$ A expressão "modo de vida" é usada aqui para se referir à natureza não somente material e física da reprodução social, ainda que não ocorra autônoma a elas. No contexto desse artigo importa reter que, embora haja alternativas e criatividade nas escolhas cotidianas, elas se dão no interior de possibilidades histórica, cultural e socialmente delimitadas.

${ }^{2} \mathrm{O}$ sentido do termo aqui empregado considera que em todos os planos, a fragilidade social de uma pessoa, de uma família, de um grupo, de uma população, ou de uma nação, interfere na qualidade da resposta em termos de sua fragilidade corporal; entrava ou altera seu tratamento e sua "reparação". $\mathrm{O}$ mesmo ocorre quando se trata de prevenir: o acesso à prevenção está marcado pelas desigualdades sociais. 
Aging and social support networks in rural area of the Pantanal in Mato Grosso, Brazil

In the process of population aging in rural area, social support networks are essential for the reproduction of the group in which, due to tradition in the rural area, the family stands out as an essential unit of economic cooperation and main source of social support in this context. Considering the dynamism of the territory, the transformations it can affect, mutually, the possibilities of this support. In this paper, aspects of social support among families of elderly farmers were focused having as a reference the notion of social network in rural area and as empiric universe two rural communities (São Pedro and Retiro São Bento), in the district of Joselândia, municipality of Barão de Melgaço, state of Mato Grosso, Brazil. It is a study guided by the socioanthropological perspective that allowed understanding the subjects' viewpoint, using the qualitative approach. Eighteen elderly people from 11 families, eight families from São Pedro and three from São Bento were interviewed. Overall, the elderly inhabitants interviewed do not separate the physical dimension of the land from its symbol - which is the whole meaning of their existence. In various everyday situations, kinship, friendship and identity joined people in reciprocity relations, for several reasons, with attention to the role of the ties for health maintenance. The support networks widen, in the case of care for diseases and other support networks are set up for the access to health services. This elasticity/plasticity from network to support combines with the notion of territoriality due to its material and symbolic connotation.

Key words: aging, rural area, social support, networks. 